\title{
Electricity demand-side management: best practice programmes for the UK
}

\author{
P. Warren \\ UCL Energy Institute, University College London, UK
}

\begin{abstract}
Electricity demand-side management (DSM) refers to technologies, actions and programmes on the demand-side of electric meters that seek to manage or decrease electricity consumption, in order to reduce overall electricity system expenditures or contribute to the achievement of policy objectives such as carbon emissions reduction or balancing electricity supply and demand. The programme and policy side of DSM has been little explored and the research contributes to filling this gap by undertaking a global systematic review of electricity-focussed DSM programme case studies to determine what constitutes best practice programmes and policies in DSM. Systematic Reviews are a method primarily used in the medical sciences and to which have had limited application in the energy policy field to date. DSM 'best practice' is defined as programmes and policies that reduce overall electricity demand or shift loads to off-peak time periods, through measures that are environmentally, economically and socially beneficial, and are transferable between regions and countries. Best practices are not static but constantly evolving as circumstances change and new evidence is brought to light. The UK is currently consulting on how to include the demandside in its Electricity Market Reform policy proposals and a key outcome of this research is to determine the transferability of international best practices to the UK to feed into this process. The research aims to determine how and why particular DSM programmes are successful or fail and what the underlying contextual factors are that could prevent or allow their transferability to the UK. This paper focuses on the findings from an extensive year-long literature review and some of the preliminary results from the Systematic Review.

Keywords: demand-side management, electricity, systematic review, energy policy, best practice, energy security, carbon emissions reduction.
\end{abstract}




\section{Introduction}

Environmental and energy security issues are increasingly moving to the forefront of the political agenda. Energy production and consumption is widely regarded as a key contributor to anthropogenic climate change. The International Energy Agency (IEA) estimates that $\sim 70 \%$ of world energy production is produced through the burning of fossil fuels, primarily coal (42\%) and gas ( $21 \%$ ), and energy accounts for $40 \%$ of anthropogenic carbon dioxide and other greenhouse gas emissions $\left(\mathrm{CO}_{2 \mathrm{e}}\right)$. The demand for energy is growing as national populations expand, particularly in emerging economies, and the growth of gadgets and technology in society continues (IEA [1]).

Balancing energy supply and demand has been a complex challenge in many countries, with back-up supply margins of $\sim 20 \%$ commonly used to deal with peak demands (Anderson [2]), such as when people turn their kettles on after a popular television programme or on a cold winter night (Bunn and Seigal [3]). However, with flexible generation plants powered by fossil fuels, matching supply with demand has been effectively administrated in most countries. Traditionally, energy utilities have invested in expanding their capacity base to deal with long-term increases in energy demand (Torriti et al. [4]). With growing awareness of the contribution of fossil fuel generation to climate change, energy utilities are coming under political pressure to diversify to low(er) carbon alternatives.

Alternative solutions to expanding the fossil-fuel-powered capacity include investing in low(er) carbon capacity, developing energy storage technologies, increasing the number of interconnections with other countries, and demand-side management (DSM). DSM, the focus of this research, refers to technologies, actions and programmes on the demand-side of energy meters that seek to manage or decrease energy consumption. This definition is proposed based on an extensive review of the DSM literature.

In 2011 , electricity constituted $18.5 \%$ of total energy consumption by fuel in the UK, which equates to $374,343 \mathrm{GWh}$ (DUKES [5]). The largest electricity consuming sectors were domestic (30\%), industry (27\%) and commercial $(21 \%)$. What role DSM could play in reducing the demands of these sectors is part of the motivation for the research. Other sectors, such as transport, fuel producers and non-electric based heating from district heating, gas and combined heat and power (CHP) are excluded to narrow the focus. This paper outlines the findings from a year-long literature review and discusses some of the preliminary results from work-in-progress from a Systematic Review of DSM programmes conducted around the world to determine and apply best practices to the UK.

\section{Contested definitions}

In broad terms, Demand-Side Management (DSM) (historically known as load management) refers to actions undertaken on the demand side (i.e. customer side) of the electric meter (Gellings and Chamberlin [6]). Clark Gellings at the US-based Electric Power Research Institute first coined the term demand-side 
management in 1984 (Gellings [7]). In the past, DSM programmes have concentrated more on the management of electricity demand rather than on (nonelectric-based) heating and transport, though DSM can encompass non-electric energy measures, such as co-generation (the production of both heat and power), district heating and heat micro-generation technologies. A review of $>200$ academic publications (primarily journal papers, books and audiovisual material) showed that definitions of DSM vary in what they include or exclude. Some publications include the management of electricity demand but not other forms of energy demand (Prüggler et al [8]), others use the definition synonymously with that of the smart(er) grid (Davito et al [9]), some refer to DSM as measures that reduce energy demand at peak times (Ofgem [10]), while others use a similar definition but also include the response of consumers to price changes and the shifting of load to off-peak times (Strbac [11]). Micro-generation is included in some definitions (Eissa [12]) and some include or exclude energy efficiency measures (Sioshansi and Vojdani [13]). However, Gellings and Chamberlin [6] gives a holistic definition:

DSM activities are those which involve actions on the demand side of the electric meter, either directly or indirectly stimulated by the utility. These activities include those commonly called load management, strategic conservation, electrification, strategic growth or deliberately increased market share.

DSM aims to match demand with the available supply as a cheaper alternative for energy utilities than investing in new generation capacity. Gellings and Chamberlin [6] argues that DSM tries to encourage utilities to put demand-side measures on an equal level with supply-side options. Furthermore, it aims to actively engage consumers in the management of their energy use and how they can save money by making their consumption more 'visible' and important to them (Stromback et al. [14]). If overall energy demand is reduced (rather than simply load shifting), DSM can reduce $\mathrm{CO}_{2 \mathrm{e}}$ emissions and overcome issues of energy security. Although Gellings and Chamberlin's [6] definition is useful, arguably it does not directly include current policy priorities in many countries to reduce energy consumption as part of the means to reduce $\mathrm{CO}_{2 \mathrm{e}}$ emissions. Eissa [12] states that the overall goal of DSM should now be to reduce overall energy demand and shift patterns of consumption to help smooth demand. Such a definition would then exclude traditional aspects of DSM, such as strategic load growth, where utilities deliberately increase loads in times of excess capacity (Gellings and Chamberlin [6]), which could become more common under conditions of surplus wind power.

From the publications consulted, twenty-two explicitly state definitions of DSM and the differences between them highlight the variations in what is considered to constitute DSM. A selection of the definitions are listed below:

Demand Side Management [is] the planning, implementation, and monitoring of utility activities designed to encourage customers to modify patterns of electricity usage, including the timing and level of electricity demand. DSM covers the complete range of load-shape objectives, including strategic 
conservation and load management, as well as strategic load growth (Kerr et al. [15]).

Kerr et al. [15] point out that DSM does not just refer to programmes that reduce overall energy demand but those that smooth out the supply-demand balance through load management and increase consumption through strategic load growth. In contrast, Didden and D'haeseleer [16] concentrates more on behavioural practices and actions that result from DSM programmes rather than specific technological or economic tools, and thus take a more sociological definition of DSM:

...many initiatives have been implemented to change consumers' behaviour towards a more efficient one. These initiatives are referred to as demand side management (DSM) (Didden and D'haeseleer [16]).

However, Eissa's [12] definition, like Gellings and Chamberlin [6], is holistic and covers a full spectrum of actions and specific technologies. The definition is more recent than Gellings and Chamberlin [6] and covers a broader set of categories: load management, energy efficiency, demand response, energy storage and distributed generation:

Load management is the process of scheduling the loads to reduce the electric energy consumption and/or the maximum demand...such as load shedding and restoring, load shifting, installing energy-efficient processes and equipment, energy storage devices, co-generation and non-conventional sources of energy, and reactive power control...Demand Response is a subset of the broader category of end-use customer energy solutions known as DSM. In addition...DSM includes energy efficiency programs (Eissa [12]).

\section{Proposed definition}

This paper proposes the following definition, which extends Eissa's [12] definition. It collates key information on the technologies, practices, instruments, programmes and policies that are included in the definitions reviewed.

Demand-side management (DSM) refers to technologies, actions and programmes on the demand-side of energy meters that seek to manage or decrease energy consumption, in order to reduce total energy system expenditures or contribute to the achievement of policy objectives such as emissions reduction or balancing supply and demand.

The research focuses more specifically on DSM that reduces or time-shifts electricity demand, particularly in the residential, commercial and industrial sectors, which often make up the highest proportions of electricity consumption.

Figure one shows a more detailed version of the proposed DSM definition, which places DSM technologies, actions and programmes into four broad categories: energy efficiency, demand response, distributed generation and distributed storage. Distributed generation is the localised production of energy from on-site back-up generation units such as diesel generators and solar panels. It is included for grid balancing purposes only to reduce the demand for energy from the grid, particularly during times of peak demand. Distributed storage refers to the storage of energy during off-peak periods, such as through hot water 
storage tanks or electric vehicle batteries, which is released during peak periods when prices are high. Similarly, it is only included for grid balancing purposes, particularly during peak times. Demand response and energy efficiency are both included in the majority of the reviewed DSM definitions. The former refers to the response of consumers to price changes or incentive payments (Albadi and El-Saadany [17]).

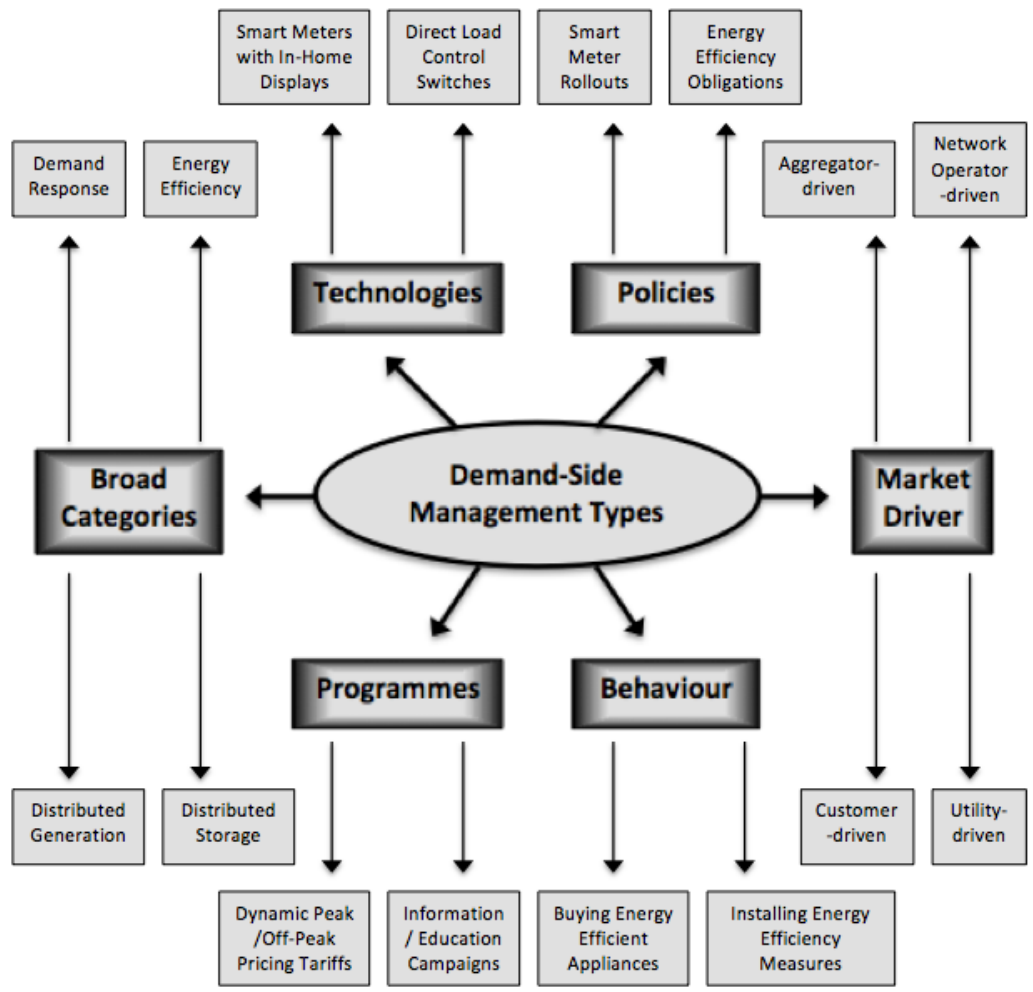

Figure 1: Categorisation of DSM types under the proposed definition.

As figure one highlights, the proposed definition includes the physical DSM measures, the instruments for implementation and behavioural actions. Hence, it includes tools/instruments, practices, actions, technologies, programmes and policies. The specific examples given are a non-exhaustive list of DSM types.

\section{Historical impacts of DSM}

Although DSM is receiving growing research and political attention due to the low carbon agenda, energy security issues and the development of the smart(er) grid, harnessing demand-side flexibility is not new (Cooke [18]). The concept of DSM in policy can be traced back to the US Public Utility Regulatory Policy Act 
1978 (PURPA) when it was first legislated in a country nationally as a solution to the energy security issues of the 1970s. PURPA's primary purpose was to promote the greater use of domestic renewable energy, but it led to the US National Energy Conservation Policy Act 978, which required utilities to offer on-site energy audits to their residential customers. Eto [19] argues that this began modern utility DSM programmes. Nevertheless, the notion of DSM has been around for longer, traditionally referring to a utility's general load management or through the use of hot water tanks and storage heaters in houses (Barrett [20]). However, PURPA was the first instance in government policy.

The 1970s energy crises particularly affected the USA and were caused by the Arab Oil Embargo of OAPEC in 1973-1974 and the Iranian Revolution in 19781979 (Hamilton [21]). PURPA introduced Integrated Resource Planning, which involves energy utilities evaluating options for meeting future electricity demands and providing energy services at minimal societal costs to customers (Cheng [22]). Options include DSM in addition to traditional supply-side options and utilities choose the least-cost combination of resources (Cheng [22]). DSM programmes grew in the USA in the 1980s and 1990s and by 1995, 600 energy utilities had conducted 2,300 programmes involving 20 million participants (Cheng [22]). Notably, between 1989 and 1995, 260,000 GWh were saved from a cumulative spending of USD 14 billion (Nadel and Geller [23]). DSM programmes declined in the USA post-1995 as energy security issues became less prominent.

DSM did not achieve the same interest or success in Europe as it did in the USA, and this is arguably due to a lack of a European equivalent to PURPA, which also pre-dated the formation of the European Union in 1993. Despite this, Gellings [24] speculated that Europe had a similar degree of development as the USA in the 1980s-1990s. Although energy conservation and energy efficiency measures were given more attention in political circles in the 1980 s following the energy crises, market liberalisation and deregulation in the 1990s removed many energy utilities' interest in DSM. The policy led to a market based on the quantity of electricity sold and many utilities perceived energy conservation at odds to the profitability of their businesses (Cheng [22]).

Despite this, there has been renewed interest in DSM in the 2000s and 2010s as a result of climate change and energy security issues coming to the forefront of the political agenda. This is in contrast to the predictions of Gellings [24], who argued that the development of DSM in developed countries would continue to decline. Recent figures show that the combined annual utility expenditure across 18 states in the USA is >USD 900 million with annual incremental savings of $\sim 2.8$ million MWh (megawatt-hours) (Crossley [25]). The International Energy Agency's DSM Programme has supported the advancement of DSM research globally since 1993 and aims to be a key source of information.

\section{DSM in the UK}

The UK is the focus of the research and this section outlines the current status of DSM in the country. The UK has a Balancing Mechanism to balance supply and 
demand during peak times, which has been dominated by back-up generation that is often inefficient, high-carbon and expensive to operate, as it is only used for a few hours per year (Bradley et al. [26]). Storage, interconnection and DSM are alternatives, though the inclusion of DSM in the Balancing Mechanism has been limited. National Grid, the system operator, had total requirements of 4.7 GW (gigawatts) in 2011-2012 and Ward et al. [27] estimates that $\sim 1.5 \mathrm{GW}$ of DSM capacity was contracted, the majority of which was provided by on-site back-up generation (mainly diesel generators) with demand response contributing 200 MW. Ancillary services can be provided through the Short Term Operating Reserve (STOR), Fast Reserve, Firm Frequency Response and Frequency Control. The $\sim 1.5 \mathrm{GW}$ of existing DSM capacity contributes mainly to STOR and is provided through interruptible/curtailment contracts with large industries.

To participate in STOR, there is a minimum requirement of $3 \mathrm{MW}$ (which can be aggregated from different sites, offering the development of a potential market for aggregators of (small) commercial and domestic loads), which can be delivered within 240 minutes for a minimum of two hours (National Grid [28]). For Fast Reserve, the requirements are the ability to deliver a minimum of $50 \mathrm{MW}$ within two minutes at a rate greater than $25 \mathrm{MW} /$ minute for a minimum of 15 minutes (National Grid [28]). Frequency response is necessary when demand exceeds the frequency of electricity supply $(50 \mathrm{~Hz}$ in the UK), causing a drop in frequency as generators (slightly) slowdown, which can occur as a result of inaccurate forecasts or a generation disruption event (Element Energy [29]). Firm Frequency Response is an automatic change in demand (or power output) in response to frequency changes and requires a minimum participation of 10 MW (National Grid [28]). Furthermore, Frequency Control through demandside participation must be available 24 hours/day and be able to deliver within two seconds for a minimum of 30 minutes, with a minimum participation capacity of $3 \mathrm{MW}$ (National Grid [28]). This can be aggregated from loads from the same site. The STOR average contracted utilisation payment from National Grid was $£ 225 / \mathrm{MWh}$ in 2011 and for Firm Reserve it was $£ 22,000 / \mathrm{MW}$ (Element Energy [29]). The economic revenue from $3 \mathrm{MW}$ of demand-side participation in STOR would be $£ 66,000 /$ year (availability revenue) and $£ 35,000-£ 55,000$ /year (utilisation revenue based on $50-80$ one hour utilisation periods per year) (Element Energy [29]). Thus, there is a role for utilities or separate DSM companies to aggregate reductions from different smaller loads to meet the requirements for entering the Balancing Mechanism.

In 2010 the total energy consumption of the non-domestic sectors was $\sim 40.6$ GW (DUKES [5]) and in 2012 it was estimated that a potential reduction of 1.2-4.4 GW was achievable under existing and proposed demand response measures in the non-domestic sectors (Element Energy [29]). Hot water has a high flexibility of $\sim 50 \%$ and lighting (through dimming and turning off nonessential lights), air conditioning units and other end uses have flexibilities of $\sim 20 \%$ (Element Energy [29]). Other potential end uses that can be voluntarily or automatically adjusted during peak periods are: heating, catering, computing and refrigeration, with the greatest (non-industrial) demand response potential in the 
UK being in the retail $(\sim 0.7 \mathrm{GW})$, education $(\sim 0.3 \mathrm{GW})$ and commercial offices $(\sim 0.3 \mathrm{GW})$ sectors (Element Energy [29]). In the residential and small commercial sectors, DTI (2005) states that $\sim 1$ GW of DSM capacity is possible.

\section{Systematic reviews}

Work-in-progress in this research is analysing global best practices in DSM and their transferability to the UK to meet the estimated potential, particularly in the residential, commercial and industrial sectors. The research undertakes a Systematic Review of DSM programmes and policies rather than specific trials as the policy side of DSM has received much less attention. Systematic Reviews are a method widely used in the medical sciences, particularly through the Cochrane Collaboration, but has had limited attention in other disciplines. However, the Campbell Collaboration is beginning to apply the method to other policy areas, such as education, crime and justice, and social welfare. Nevertheless, the method has not yet been applied to the energy policy field and there have been calls for this to be undertaken (Sorrell [30]). The method involves synthesising all the work that has been done on a particular intervention, trial or programme to better understand what works and what does not (Petticrew and Roberts [31]). Works that may be included are published and unpublished material, academic and 'gray' literature (such as policy documents and industrial reports), and peer reviewed and non-peer reviewed documents. However, a key part of the Systematic Review, unlike traditional reviews, is the detailing of a search strategy, inclusion and exclusion criteria, and critical appraisal of the methodological quality of the documents reviewed (Petticrew and Roberts [31]).

Systematic Reviews can be classified into those that are more configurative and interpretive (mainly qualitative, though can have some quantitative aspects), and those that are more aggregative and integrative (mainly quantitative, though can have some qualitative aspects) (Dixon-Woods et al. [32]). The former includes: narrative summary, thematic analysis, grounded theory and metaethnography, whereas the latter includes: meta-study, statistical meta-analysis, Miles and Huberman's cross-case techniques, content analysis, case survey and qualitative comparative analysis (Dixon-Woods et al. [32]). Some types, such as Realist Synthesis, originally proposed by Pawson [33], are mixed methods and involve both qualitative and quantitative aspects. The research employs a Realist Synthesis as the method's primary strength is in understanding how and why particular programmes work by examining the underlying mechanisms that determine whether they succeed or fail (Pawson [33]).

A number of methodological quality assessment scales have been developed in the fields that now use Systematic Reviews. In the medical sciences, the Jadad scale is widely used, and involves a number of 'yes/no' answers being given to questions on whether or not the study was randomised, blind and the stating of withdrawal rates. However, DSM programmes vary greatly not only in the type of DSM studied, but the way the programmes were implemented and evaluated and who administrated the process (governments, utilities, institutions, etc.). In 
the medical sciences, interventions tend to be undertaken by academics or industry experts, often using homogenous methods, and the results are peer reviewed. In the DSM field, and which is usually the case in social science fields, programmes are too heterogeneous to each other to be statistically aggregated and it is often inappropriate, as they are undertaken in particular national or regional contexts and highlight that what works in one place may not work in another (Petticrew and Roberts [31]). Thus, what is more useful for policy is to understand the mechanisms behind how and why a programme works and to assess the similarities and differences in contextual factors between places that may impact on their transferability. Thus, DSM studies tend to be less rigorously conducted methodologically and often do not include randomisation, blinding and statements of withdrawal rates. Hence, the proposed scale below is adapted to suggest how to conduct Systematic Reviews in the energy policy field.

1. 4 points: has the process for programme implementation been clearly explained (who collected the data, details of the sampling procedure adopted and associated errors, and whether or not the participant takeup/drop-out rates are given)?

2. 4 points: has the process for programme evaluation been clearly explained (the method used and why it was used, who evaluated the data and potential biases, and the objectivity of the reported results in terms of the stating of negative results)?

3. 2 points: has the document been peer reviewed or independently verified by an established assessor?

4. 2 points: are there copyright statements, statements of compliance with regulatory requirements and statements regarding possible conflicts of interest in the document?

5. 1 point: is the authority of the publishing organisation reliable and reputable?

6. 1 point: where percentages are given, are the totals given?

Each question is initially worth one point but a further six points are added to weight the questions by importance. Hence the maximum score that can be achieved is 12 points and the minimum score is 0 . The documents must score at least half of the available points to be included in the analysis (i.e. 6 points). Well-known scales like the Jadad Scale often have a two-thirds threshold. However, as many of the studies in this research are likely to be heterogeneous to each other and situated in quite different contexts, as well as being few in number, the lower threshold of half is used to include potentially important studies that would otherwise fail the quality assessment scale due to not including 'surface' features, such as statements of compliance or conflicts of interest. The review synthesises the following information, where given: 
- DSM programme key criteria (quantitative):

O Overall energy savings

- Peak load reduction

- Programme costs to utilities

- Carbon savings

- Energy bill savings

- Utility profitability (or revenue-neutrality)

- (Potential) Revenue losses for utilities

o Programme costs to government

- Programme costs to consumers

○ Deferred investment in generation infrastructure

- DSM programme mechanisms (qualitative):

- Why certain DSM programmes were chosen

- How the DSM programme was implemented

- Stated information on the success of the programme (whether it was successful and how and why it worked or failed)

○ How the DSM programme was evaluated

- DSM programme context (qualitative):

- Electricity system structure

- Electricity market structure

○ Degree of government intervention

- Consumer awareness and familiarity with DSM

The analysis of the DSM programme key criteria and mechanisms will determine what constitutes best practice in DSM programmes, and the assessment of the contextual factors will establish the transferability of specific programmes to the UK, providing policy recommendations. At the time of writing, the year-long Systematic Review is in progress and preliminary results will be discussed at the Energy and Sustainability 2013 conference.

\section{Conclusion}

Climate change and energy security issues are increasingly moving to the forefront of the political agenda. Historically, there has been a concentration on supply-side solutions, but in the face of current high investment costs for many low(er) carbon power options and the variability of preferred options, such as wind power, energy utilities are looking for alternative ways to meet the growing pressures from governments, stakeholders and the public. Alternative solutions include energy storage, cross-border interconnections and DSM. Most storage technologies are in the early stages of development and interconnections increase the dependence on foreign energy supplies. Hence, there is great potential for DSM to play an important and complementary role.

DSM traditionally referred to load management, including measures that reduced (conservation), smoothed (time-shifted load and peak load reduction) or increased (strategic load growth) energy demand to help balance supply and demand. However, the proposed research puts forth a holistic definition that is 
more tailored to current policy objectives for carbon emissions reduction and energy security. The paper discussed the findings of a year-long literature review on DSM, consulting $\sim 200$ academic publications and $\sim 200$ documents in the 'gray' literature, and outlined work-in-progress that is applying the method of Systematic Reviews to the energy policy field. The research is undertaking a Realist Synthesis of DSM programmes conducted around the world to determine what constitutes best practice, and what could be transferred to the UK based on an analysis of the contextual factors impacting the degree of transferability.

\section{References}

[1] International Energy Agency (IEA) Gadgets and Gigawatts - Policies for Energy Efficient Electronics, Paris, IEA, 2009

[2] Anderson, D. Power System Reserves and Costs with Intermittent Generation, Working Paper, UK Energy Research Centre (UKERC), 2006

[3] Bunn, D.W. and Seigal, J.P. Television peaks in electricity demand, Energy Economics, January, 1983

[4] Torriti, J., Hassan, M.G. and Leach, M. Demand response experience in Europe: policies, programmes and implementation, Energy, 35, 4, 2010

[5] Department of Energy and Climate Change Digest of UK Energy Statistics 2012, www.decc.gov.uk/en/content/cms/statistics/publications/dukes.aspx

[6] Gellings, C.W. and Chamberlin, J.H. Demand-Side Management: Concepts and Methods, $2^{\text {nd }}$ Edition, The Fairmont Press, Inc., USA, 1993

[7] Gellings, C.W. The concept of demand-side management for electric utilities, Proceedings of the IEEE, 73, 10, 1985

[8] Prüggler, N., Prüggler, W. and Wirl, F. Storage and Demand Side Management as power generator's strategic instruments to influence demand and prices, Energy, 36, 6308-6317, 2011

[9] Davito, B., Tai, H. and Uhlaner, R. The smart grid and the promise of demand-side management, Mckinsey and Company, 2010

[10] Office of Gas and Electricity Markets Smart Metering Implementation Programme: Statement of Design Requirements, 2010

[11] Strbac, G. Demand side management: benefits and challenges, Energy Policy, 36, 4419-4426, 2008

[12] Eissa, M.M. Demand side management program evaluation based on industrial and commercial field data, Energy Policy, 39, 5961-5969, 2011

[13] Sioshansi, F. and Vojdani, A. What could possibly be better than real-time pricing? Demand Response, The Electricity Journal, June, 2001

[14] Stromback, J., Dromacque, C. and Yassin, M.H. The potential of smart meter enabled programs to increase energy and systems efficiency: a mass pilot comparison, Vaasaett, 2011

[15] Kerr, D., Lemaire, X. and Owen, G. An annotated bibliography and reference guide on energy efficiency and demand side management, SERN Literature Review 2011, University College London, London, UK, 2011

[16] Didden, M.H. and D'haeseleer, W.D. Demand Side Management in a competitive European market: who should be responsible for its implementation? Energy Policy, 31, 1307-1314, 2003 
[17] Albadi, M.H. and El-Saadany, E.H. A summary of demand response in electricity markets, Electric Power Systems Research, 78, 1989-1996, 2008

[18] Cooke, D. Empowering Customer Choice in Electricity Markets, Information Paper, October 2011, International Energy Agency (IEA), 2011

[19] Eto, J. The Past, Present and Future of U.S. Utility Demand-Side Management Programs, Ernest Orlando Lawrence Berkeley National Laboratory, University of California, USA, 1996

[20] Barrett, M. A renewable electricity system for the UK, Response to the 2006 Energy Review, University College London (UCL), London, UK, 2006

[21] Hamilton, J.D. Historical Oil Shocks, NBER Working Paper Series, Working Paper 16790, National Bureau of Economic Research, Cambridge, USA, http://www.nber.org/papers/w16790, 2011

[22] Cheng, C-C. Electricity demand-side management for an energy efficient future in China: technology options and policy priorities, $\mathrm{PhD}$ Thesis, Massachusetts Institute of Technology, USA, 2005

[23] Nadel, S. and Geller, H. Utility DSM: what have we learned? Where are we going?, Energy Policy, 24, 4, 289-302, 1996

[24] Gellings, C. W. Before demand-side management is discarded, let's see what pieces should be kept, OPEC Review, 24, 1, 61-70, 2000

[25] Crossley, D. International Best Practice in using Energy Efficiency and Demand Management to support Electricity Networks, Report 4 of the Australian Alliance to Save Energy Research Project: Scaling the Peaks: Demand Management and Electricity Networks, Australia, 2010

[26] Bradley, P., Leach, M. and Torriti, J. A review of current and future costs and benefits of demand response for electricity, Centre for Environmental Strategy, University of Surrey, UK, 2011

[27] Ward, J., Pooley, M. and Owen, G. GB Electricity Demand - realising the resource: Paper 4: What demand side services can provide value to the electricity sector?, Paper 4 of the GB Electricity Demand - realising the resource project, Sustainability First, UK, June, 2012

[28] National Grid Demand Side Opportunities, http://www.nationalgrid.com /NR/rdonlyres/BE8D8515-7325-43C3-A8FB85249BA9E76B/38375/Demand_Side_Opportunities.pdf, 2011

[29] Element Energy Demand side response in the non-domestic sector, Final Report for Ofgem, with De Montford University, Leicester, UK, 2012

[30] Sorrell, S. Improving the evidence base for energy policy: the role of systematic reviews, Energy Policy, 35, 1858-1871, 2007

[31] Petticrew, M. and Roberts, H. Systematic Reviews in the Social Sciences, Blackwell Publishing, Oxford, UK, 2006

[32] Dixon-Woods, M., Agarwal, S., Jones, D., Young, B. and Sutton, A. Synthesising qualitative and quantitative evidence - a review of possible methods, Journal of Health Services Research Policy, 10, 1, 45-53, 2005

[33] Pawson, R. Evidence-based policy: the promise of 'Realist Synthesis', Evaluation, 8, 3, 340-35, 2002 